\title{
The Inducible Quinate-Shikimate Catabolic Pathway in Neurospora crassa: Induction and Regulation of Enzyme Synthesis*
}

\author{
By R. S. CHALEFF $\dagger$ \\ Department of Biology, Kline Biology Tower, Yale University, New Haven, \\ Connecticut 06520, U.S.A. \\ (Received I6 July 1973) \\ SUMMARY \\ The regulation of the synthesis of the first three enzymes of the quinate- \\ shikimate catabolic pathway in Neurospora crassa has been studied. Induction of \\ these enzymes is promoted efficiently by quinate and less so by 5-dehydroquinate \\ and/or 5-dehydroshikimate. Shikimate has little or no inducing ability. The kinetics \\ and steady-state rates of synthesis of the three catabolic enzymes have been exa- \\ mined. It is suggested that quinate-shikimate dehydrogenase, catabolic dehydro- \\ quinase, and 5-dehydroshikimate dehydrase are regulated coordinately.
}

\section{INTRODUCTION}

The first four activities of the quinate-shikimate catabolic pathway.in Neurospora crassa are controlled by four closely linked genes (Rines, I969; Chaleff, 1974). One of these loci, qa-I, encodes a multimeric regulatory protein (Valone, Case \& Giles, I971; Case, 1972; Partridge, Case \& Giles, 1972). The $q a-2$ and $q a-3$ loci are the structural genes for catabolic dehydroquinase (5-dehydroquinate hydro-lyase, EC. 4.2.1.10) and quinate-shikimate dehydrogenase (quinate:NAD oxidoreductase, EC. I . I . I .24) respectively. The qa-4 region is probably the structural gene for dehydroshikimate dehydrase (Rines, 1969; Chaleff, 1974). Although no evidence exists for a polycistronic messenger RNA in this system, the clustering of the $q a-2, q a-3$ and $q a-4$ genes suggests that these genes may constitute an operon. To determine whether the organization of the quinate-shikimate pathway satisfies another aspect of the definition of an operon, studies on the regulation of the synthesis of the three enzymes were undertaken. The operon model demands that the ratio of the synthetic rate of any enzyme to that of any other enzyme in the same operon remain constant under all conditions of growth (Ames \& Garry, 1959; Ames \& Martin, 1964).

In previous studies those compounds which induce synthesis of the catabolic enzymes were not identified completely (Giles, Partridge, Ahmed \& Case, I967; Rines, 1969). Experiments are described here in which double mutant strains which accumulate specific intermediates were used to define further those metabolites which function as inducers of this pathway.

\section{METHODS}

The origin of strains and the conditions of growth and extraction are described by Chaleff (1974). Constitutive mutants $\left(q a-I^{\mathrm{C}}\right)$ were originally isolated by Valone et al. (I97I).

Induction medium. Induction media contained $\mathrm{I} \cdot 5 \%(\mathrm{w} / \mathrm{v})$ glycerol as carbon source.

* Adapted from a thesis submitted to the faculty of Yale University in partial fulfilment of requirements for the degree of Doctor of Philosophy.

$\dagger$ Present address: Biology Department, Brookhaven National Laboratory, Upton, New York I 1973 , U.S.A. 
Table I. Enzyme levels in several strains following growth in the absence or in the presence of various inducing compounds

\begin{tabular}{|c|c|c|c|c|c|c|c|}
\hline \multirow[b]{2}{*}{ Genotype } & \multirow[b]{2}{*}{ Strain } & \multirow[b]{2}{*}{ Inducer } & \multicolumn{5}{|c|}{ Specific activities in extracts* } \\
\hline & & & QDH & SDH & $\begin{array}{l}\text { Catabolic } \\
\text { DHQase }\end{array}$ & $\begin{array}{c}\text { DHS } \\
\text { dehydrase }\end{array}$ & $\begin{array}{c}\text { PCA } \\
\text { oxygenase }\end{array}$ \\
\hline Wild type & $74 \mathrm{~A}$ & 0 & 0.4 & $12 \cdot I$ & 0.0 & 0.2 & 0.0 \\
\hline Wild type & $74 \mathrm{~A}$ & $0.3 \%$ QA & $156 \cdot 2$ & $377^{\circ} 0$ & $296 \cdot 3$ & $54 \cdot 5$ & $58 \cdot 5$ \\
\hline Wild type & $74 \mathrm{~A}$ & $0.3 \% \mathrm{SA}$ & $4 I \cdot 3$ & 159.0 & $6 I \cdot 5$ & $22 \cdot 3$ & 30.0 \\
\hline Wild type & $74 \mathrm{~A}$ & $0.1 \% \mathrm{DHQ}$ & $48 \cdot 2$ & $179 \cdot 0$ & 49.0 & $17 \cdot 2$ & $30 \cdot 8$ \\
\hline arom-2 & 82 & 0 & $3 \cdot 7$ & $18 \cdot 9$ & 0.2 & N.T. & N.T. \\
\hline arom-I & I 183 & 0 & $26 \cdot 0$ & $58 \cdot 1$ & $188 \cdot 3$ & II $\cdot I$ & N.T. \\
\hline aromt-9 & M6-II & 0 & $17 \cdot 7$ & 70.2 & $80 \cdot 3$ & $13 \cdot 2$ & $I \cdot 0$ \\
\hline qa-3 arom-I & MI6; II83 & 0 & 0.0 & 0 & 1420.4 & $250 \cdot 3$ & I $5 \cdot 5$ \\
\hline qa-3 arom-9 & MI6; M6-I I & 0 & $0 \cdot 0$ & 9.5 & 154.0 & $40 \cdot I$ & 4.5 \\
\hline$q a-I^{\mathrm{F}}$ arom-I & I59; I I 83 & 0 & $2 \cdot I$ & $4 \cdot 2$ & 0.5 & $4 \cdot 0$ & N.T. \\
\hline$q a-I^{\mathrm{F}}$ arom-9 & I 59; M6-I I & 0 & $2 \cdot 2$ & II 4 & 0.0 & 0.3 & N.T. \\
\hline$q a-3$ & MI6-IA & $0.3 \% \mathrm{QA}$ & 0.0 & $12 \cdot I$ & $776 \cdot 1$ & $401 \cdot 3$ & N.T. \\
\hline$q a-3$ & M22-IA & $0.3 \%$ QA & 0.0 & I I $\cdot 2$ & $496 \cdot 0$ & $39 I \cdot 2$ & N.T. \\
\hline$q a-3$ & MI6A & $0.1 \%$ DHQ & 0.5 & $36 \cdot 4$ & $86 \cdot 3$ & $3 I \cdot 9$ & $32 \cdot 9$ \\
\hline
\end{tabular}

* Cultures were grown on appropriately supplemented medium for $30 \mathrm{~h}$. Where it is indicated, mycelia were shifted to a minimal medium containing the designated inducer. After $8 \mathrm{~h}$, cultures were harvested and extracted by Procedure I. N.T. $=$ Not tested.

The inducing compound was added to a final concentration which is indicated for each experiment. Inducer was omitted from control cultures.

Measurement of enzyme stability in vivo. Mycelia were grown on $\mathrm{I} \cdot 5 \%$ sucrose minimal medium for $30 \mathrm{~h}$ on a rotary shaker. In experiments using a qa-3 strain, the cultures were washed with minimal medium and transferred to an induction medium containing $0.3 \%$ quinate plus $\mathrm{I} \cdot 5 \%$ glycerol. After $5 \mathrm{~h}$ the induced cultures were shifted to $\mathrm{I} \cdot 5 \%$ glycerol minimal medium containing $20 \mu \mathrm{g} / \mathrm{ml}$ cycloheximide. Cultures were harvested at the indicated intervals. In experiments using constitutive $\left(q a-I^{\circ}\right)$ strains, cycloheximide was added directly to the growth medium to a final concentration of $20 \mu \mathrm{g} / \mathrm{ml}$ after $30 \mathrm{~h}$ of growth, incubation was continued, and cultures were harvested at the times indicated.

Cycloheximide. Concentrated solutions of cycloheximide (Acti-dione; Calbiochem) were sterilized by filtration before addition to cool, autoclaved media.

\section{The nature of the inducer}

\section{RESULTS}

It was unclear from previous studies (Giles et al. 1967; Rines, 1969) whether quinate (QA), shikimate (SA) and 5-dehydroquinate (DHQ) themselves function as inducers of the enzymes of the catabolic pathway, or whether they first must be converted to other compounds within the cell for induction to occur. The nature of the inducer in vivo was sought by examining the enzyme levels in wild type and in several mutants grown under a variety of conditions. The results in Table I demonstrate the inducibility of the catabolic enzymes in wild type by QA, SA and DHQ. The very high activities in qa-3 strains which have been shifted to quinate medium suggest that either quinate or a compound formed from quinate by an enzyme other than the dehydrogenase is a powerful inducer. For details of Procedures I and II, see Chaleff (1974).

DHQ is accumulated and converted to 5-dehydroshikimate (DHS) by the catabolic dehydroquinase in an arom-9 strain grown on sucrose minimal medium (Rines, Case \& 
Giles, I969). An arom-I strain grown on polyaromatic sucrose medium accumulates both DHQ and DHS (Tatum, Gross, Ehrensvärd \& Garnjobst, 1954). The catabolic activities are found in extracts of both of these strains (Table I). These enzymes are essentially absent from an arom-2 strain which cannot synthesize DHQ (Giles et al. 1967). To determine whether induction is promoted by DHQ and/or DHS, or by quinate which is formed from these compounds in vivo, a qa-3 allele was introduced into both the arom-I and arom-9 strains. Presumably in these double mutants the accumulated intermediates cannot be converted to quinate or shikimate. Both catabolic dehydroquinase and DHS dehydrase were induced in the $q a-3$ arom- $I$ and $q a-3$ arom- 9 strains, indicating that DHQ and/or DHS (or a product of these other than quinate or shikimate) were inducers (Table I). This conclusion is supported by the observed induction of the catabolic enzymes in a qa-3 strain which has been exposed to DHQ. Since both DHQ and DHS are accumulated in cells grown under all these conditions, these experiments do not indicate whether only one or both of these compounds function as inducers in vivo. Catabolite repression may be responsible for the low levels of protocatechuate oxygenase in the extracts of the qa-3 arom-I and qa-3 arom-9 strains grown on sucrose (Table I). When an arom-I strain is grown on sucrose, protocatechuate (PCA) is initially accumulated in the medium and is metabolized only when the sucrose has been depleted (Tatum et al. 1954).

The introduction of a $q a-I^{\mathrm{F}}$ allele into the arom- $I$ and arom- 9 strains eliminated all induction (Table I). The catabolic enzymes are also absent from $q a-r$ strains which have been exposed to quinate (Rines et al. 1969; Chaleff, 1974). It appears, therefore, that quinate, DHQ, and/or DHS exert their inductive effect through interaction with the same regulatory molecule which is encoded in the $q a-I^{+}$gene.

The apparent ability of shikimate to promote induction of the quinate-shikimate catabolic enzymes was first observed by Rines (1969). Catabolic enzymes were detected in extracts of wild-type and $q a-3$ mycelia which had been exposed to $0.3 \%$ ( $17 \cdot 2 \mathrm{mM}$ ) and $0.2 \%$ (I I.4 mM) shikimate, respectively, for $8 \mathrm{~h}$ (Table I; Chaleff, I974). The levels of the enzymes in the shikimate-induced cultures were lower than those in cultures which had been exposed to the same concentration of quinate. This result prompted an examination of the relative effectiveness of the two compounds as inducers. Concentrations of shikimate as high as ro $\mathrm{mM}$ did not promote enzyme synthesis in $q a-4$ cultures and induced only very low levels of the catabolic enzymes in $q a-3$ cultures (Table 2). This level of enzyme synthesis was effected in a qa-3 strain by $5 \times \mathrm{IO}^{-7} \mathrm{M}$-quinate (Fig. 4). The enormous difference between the abilities of the two compounds to promote enzyme synthesis made it impossible to determine whether shikimate were merely a very poor inducer or if induction were accomplished by trace levels of quinate in the shikimate preparation. The lack of induction in the $q a-4$ strain suggests that in the $5 \mathrm{~h}$ period quantities of DHS sufficient to effect end-product induction are not formed from shikimate by basal levels of shikimate dehydrogenase, SDH (assuming that DHS has some inducing capacity). These results demonstrate that a high degree of structural specificity exists for the inducer. The ability of Neurospora to utilize shikimate as a sole carbon source may depend upon end-product induction of enzyme synthesis resulting from the slow conversion (either spontaneous or by trace levels of SDH) of shikimate to DHS.

\section{The kinetics of induction}

The kinetics of induction of the quinate-shikimate catabolic enzymes have been examined to determine whether the synthesis of these enzymes is controlled by separate mechanisms. To approximate a constant concentration of inducer, a mutant in which degradation of quinate is blocked was used. 
Table 2. Induction of catabolic enzymes by shikimate

\begin{tabular}{|c|c|c|c|c|c|}
\hline \multirow[b]{2}{*}{ Genotype } & \multirow[b]{2}{*}{ Strain } & \multirow[b]{2}{*}{$\begin{array}{c}\text { Shikimate } \\
\text { concentration } \\
\text { (M) }\end{array}$} & \multicolumn{3}{|c|}{ Specific activities in extracts* } \\
\hline & & & QDH & $\begin{array}{l}\text { Catabolic } \\
\text { DHQase }\end{array}$ & $\begin{array}{c}\text { DHS } \\
\text { dehydrase }\end{array}$ \\
\hline$q a-3$ & MI6-IA & $\begin{array}{l}0 \\
10^{-3} \\
10^{-2}\end{array}$ & $\begin{array}{l}0 \\
0 \\
0\end{array}$ & $\begin{array}{l}3 \cdot 6 \\
2 \cdot 9 \\
6 \cdot 8\end{array}$ & $\begin{array}{l}0 \\
0 \\
2 \cdot 7\end{array}$ \\
\hline$q a-4$ & MI 8-IA & $\begin{array}{l}0 \\
10^{-3} \\
10^{-2}\end{array}$ & $\begin{array}{l}0 \\
0 \\
0\end{array}$ & $\begin{array}{l}0 \\
0 \\
0\end{array}$ & $\begin{array}{l}0 \\
0 \\
0\end{array}$ \\
\hline
\end{tabular}

* Mycelia were grown on sucrose minimal medium for $30 \mathrm{~h}$ and were shifted to a medium containing $\mathrm{I} \cdot 5 \%$ glycerol and the indicated concentration of shikimate. After $5 \mathrm{~h}$, the cultures were harvested and extracted by Procedure II.

The differential rates of synthesis of catabolic dehydroquinase and DHS dehydrase were followed in a $q a-3$ strain which had been transferred to a medium containing $0.3 \%$ ( $15.6 \mathrm{~mm})$ quinate and $\mathrm{I} \cdot 5 \%$ glycerol following growth on sucrose (Fig. I). Although the results varied between experiments, in all cases an extrapolation from the linear section of the plot indicated that synthesis of the two enzymes was initiated simultaneously. However, it was apparent that the two activities began to increase at different rates after $3 \mathrm{~h}$. The change in the rates of appearance of the two activities may be due to a real change in the rates at which the enzymes were being synthesized or may simply reflect a differential lability of the enzymes.

The decay of catabolic dehydroquinase and DHS dehydrase activities was followed in induced cultures which were incubated in the presence of an inhibitor of protein synthesis. Pall (1966) has shown that $20 \mu \mathrm{g} / \mathrm{ml}$ cycloheximide inhibits $98 \%$ of Neurospora protein synthesis. Hawley \& Greenawalt (1970) reported $98 \%$ inhibition of protein synthesis in Neurospora by $30 \mu \mathrm{g} / \mathrm{ml}$ cycloheximide and demonstrated that the remaining $2 \%$ occurs in the mitochondria. In several experiments it was established that no induction occurs when $20 \mu \mathrm{g} / \mathrm{ml}$ cycloheximide are added at the same time as the inducer. These results are in agreement with similar experiments by Rines (1969) who first demonstrated that induction of the catabolic enzymes is dependent upon protein synthesis. The results in Fig. 2 indicate that DHS dehydrase is more labile in vivo $(2.5 \mathrm{~h}$ half-life) than is catabolic dehydroquinase. The experiments reported in Table 3 demonstrate that $20 \mu \mathrm{g} / \mathrm{ml}$ cycloheximide do not affect DHS dehydrase activity in vitro. Therefore, the loss of activity in vivo is due either to the lability of the enzyme or to proteolysis. The differential lability of DHS dehydrase in vivo means that the different rates at which catabolic dehydroquinase and DHS dehydrase activities increase with time (Fig. I) may not be caused by different rates of synthesis of these two enzymes. In subsequent experiments the error introduced by the in vivo denaturation of DHS dehydrase was minimized by harvesting cultures after a $2 \mathrm{~h}$ induction period. The averaged results of several experiments which followed the kinetics of induction of QDH, SDH, and catabolic dehydroquinase are shown in Fig. 3. The $q a-4$ strain which was used degrades quinate and DHQ to DHS. Presumably each cell contains an ever-varying mixture of quinate, DHQ, DHS, and possibly shikimate. Although both the quantity and quality of the inducer were changing during the course of the experiment, the rates at which the three activities were synthesized were indistinguishable. These results suggest that protein turnover is not a serious problem in the quantitative measurement of the quinateshikimate dehydrogenase and catabolic dehydroquinase enzymes. 


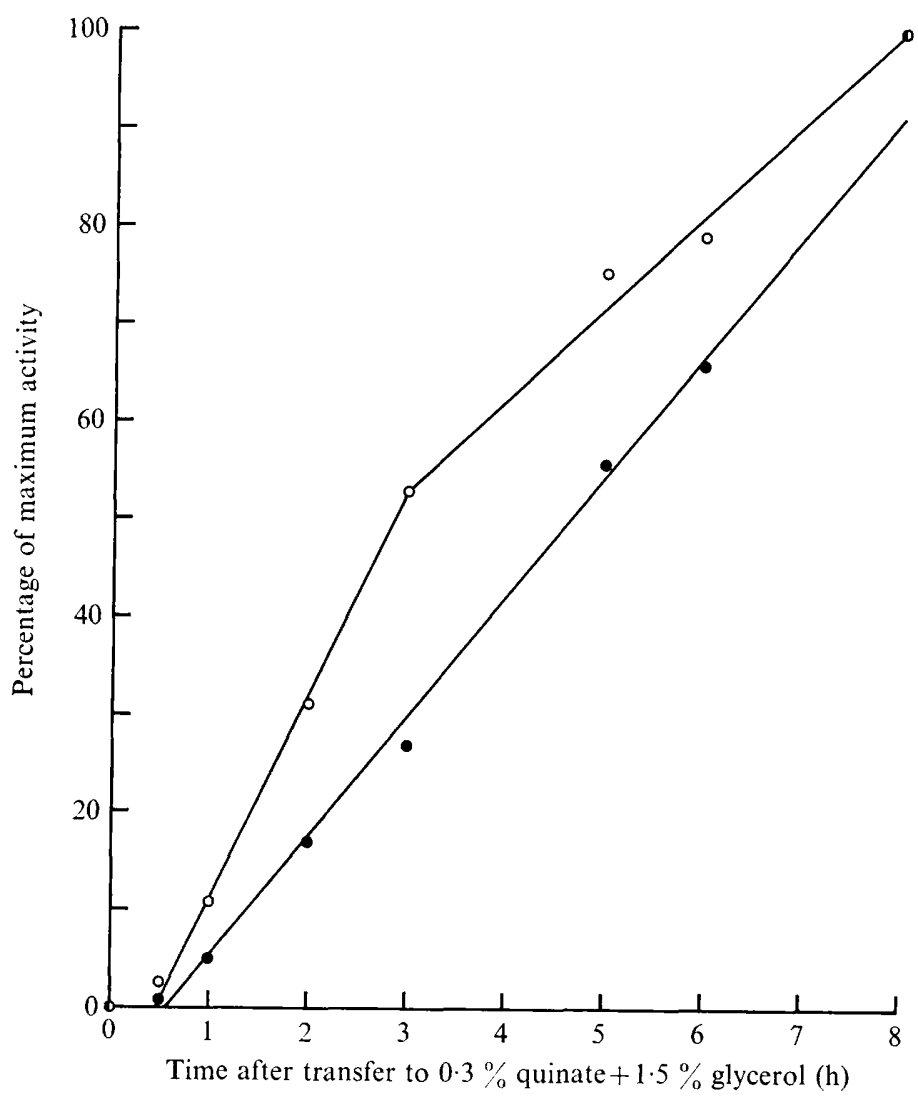

Fig. I. Induction kinetics of catabolic dehydroquinase and DHS dehydrase. Cultures of a $q a-3$ strain (MI6-IA) were grown on sucrose minimal medium for $30 \mathrm{~h}$ and were shifted to an induction medium containing $0.3 \%$ quinate and $\mathrm{I} \cdot 5 \%$ glycerol. Mycelia were harvested at the times indicated and were extracted by Procedure II. O, Catabolic dehydroquinase; $O$, DHS dehydrase.

\section{The induction profile}

The synthesis of the first three enzymes of quinate and shikimate catabolism appeared inseparable by gross kinetic analysis. A more sensitive means of detecting differences between regulatory mechanisms was provided by a measurement of the steady-state differential rate of enzyme synthesis as a function of inducer concentration. In the presence of different concentrations of inducer, presumably different proportions of the population of $q a-I^{+}$ protein molecules are in an active configuration (capable of promoting enzyme synthesis). Thus, if it is assumed that the regulatory protein functions by interacting with a regulatory site on the DNA, the competition between different regulatory sites for available regulatory protein may be determined from the rates of enzyme synthesis over a wide range of inducer concentration. In effect, the induction profile would titrate for the number of different regulatory sites with which the $q a-I^{+}$protein interacts. Superimposable profiles are consistent with either one regulatory site controlling synthesis of a polycistronic message or with several regulatory elements which have nearly identical affinities for the regulatory protein.

Figs. I and 3 indicate that steady-state synthesis of the catabolic enzymes occurred approximately $2 \mathrm{~h}$ after transfer to an induction medium. Under these conditions the rates at which the catabolic enzymes are being synthesized are a function only of inducer concentration 


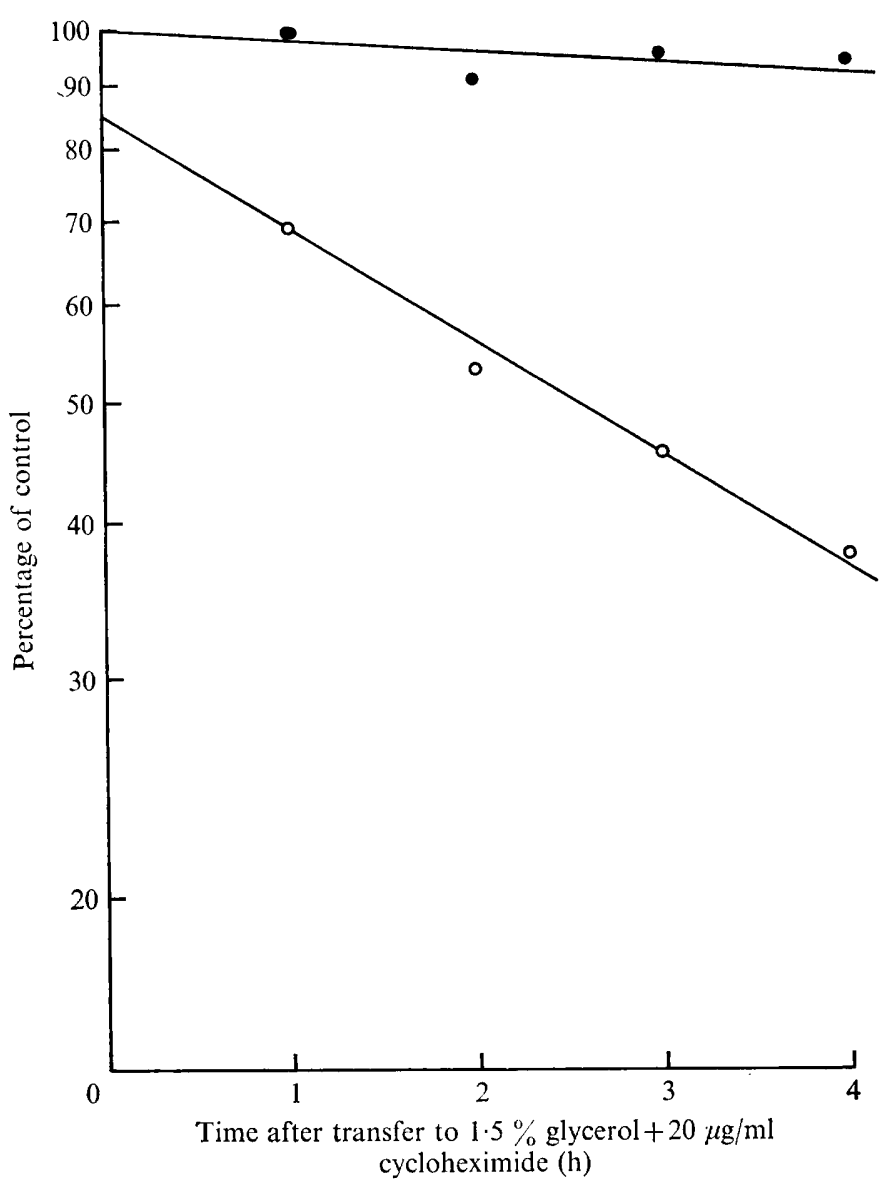

Fig. 2. Stability of catabolic dehydroquinase and DHS dehydrase in vivo. Cultures of a qa-3 strain (MI6-IA) were grown on sucrose minimal medium for $30 \mathrm{~h}$ and were shifted to an induction medium containing $0.3 \%$ quinate and $1.5 \%$ glycerol. After $5 \mathrm{~h}$ the cultures were transferred to medium containing $1.5 \%$ glycerol and $20 \mu \mathrm{g}$ cycloheximide $/ \mathrm{ml}$. Mycelia were harvested at the times indicated and were extracted by Procedure II. Values are given as a percentage of the activities in an induced control culture which was not transferred to cycloheximide medium. $\bullet$, Catabolic dehydroquinase; O, DHS dehydrase.

Table 3. Stability of DHS dehydrase in vitro

\begin{tabular}{|c|c|c|}
\hline \multirow[b]{2}{*}{$\begin{array}{l}\text { Time at } 4{ }^{\circ} \mathrm{C} \\
\text { (h) }\end{array}$} & \multicolumn{2}{|c|}{ Enzyme activity* } \\
\hline & $\begin{array}{c}\text { Without } \\
\text { cycloheximide }\end{array}$ & $\begin{array}{c}\text { With } \\
\text { cycloheximide }\end{array}$ \\
\hline 0 & 100 & 100 \\
\hline 19 & 100 & 96 \\
\hline 30 & 74 & 74 \\
\hline
\end{tabular}

* Values are reported as percentages of the activity at time zero. Extract was prepared by Procedure II from a qa-2(203)arom-9A culture which had been grown on polyaromatic sucrose medium for $30 \mathrm{~h}$ and shifted to polyaromatic $0.3 \%$ quinate medium for $5 \mathrm{~h}$. 


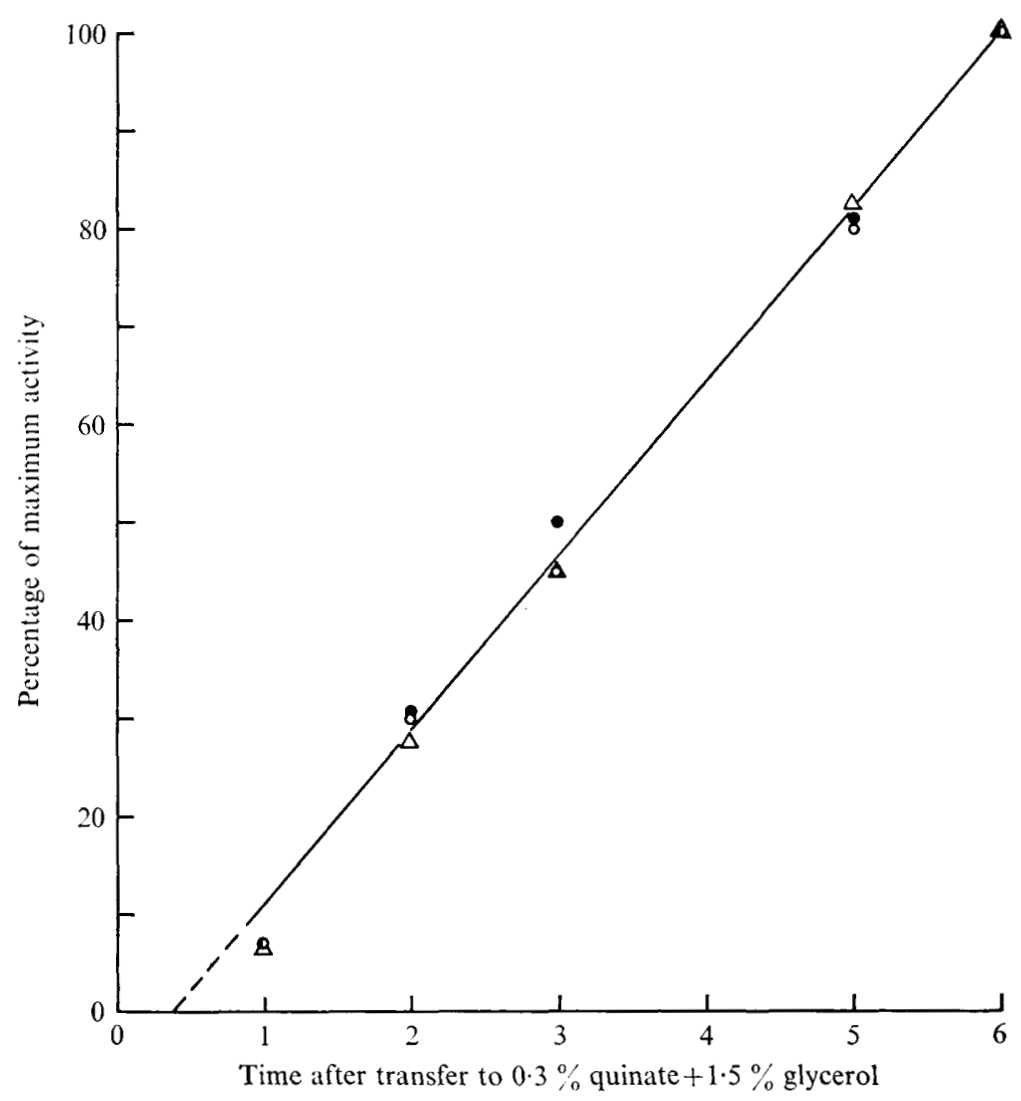

Fig. 3. Induction kinetics of QDH, SDH and catabolic dehydroquinase: cultures of a qa-4 strain (MI 8-IA) were grown on sucrose minimal medium for $30 \mathrm{~h}$ and were shifted to an induction medium containing $0.3 \%$ quinate and $1.5 \%$ glycerol. Mycelia were harvested at the times indicated and were extracted by Procedure II. Q, QDH; O, SDH; $\triangle$, catabolic dehydroquinase.

and not of limiting physiological factors. Cultures of $q a-3$ mycelia were harvested following a $2 \mathrm{~h}$ induction period on media containing different concentrations of quinate. The rates of synthesis of catabolic dehydroquinase and of DHS dehydrase exhibited an identical dependence on inducer concentration (Fig. 4). Induction was promoted by exogenous quinate concentrations as low as $5 \times 10^{-7} \mathrm{M}$ and gradually approached a maximum rate at $10^{-4} \mathrm{M}$. At half-maximal induction the quinate concentration was approximately $5 \times 10^{-6} \mathrm{M}$. It is not known whether Neurospora possesses a permease for quinate and interpretation of the induction profile would be complicated by an inducible quinate transport system. The question of a permease, however, did not interfere with a comparison of the relative rates of synthesis of the two enzymes. Once again the results were negative, in that no distinction could be made between the regulation of catabolic dehydroquinase and DHS dehydrase synthesis.

The synthesis of catabolic dehydroquinase was examined over a 200 -fold range of quinate concentrations in a qa-4 strain (Table 4). The exogenous quinate concentration at half-maximal induction was $5 \times 10^{-5} \mathrm{M}$ which is 10 times the concentration at which half-maximal induction was realized in the $q a-3$ strain. This difference was probably caused by partial degradation of the inducer by the $q a-4$ strain. Thus, using the $q a-4$ mutant, the effective concentration 


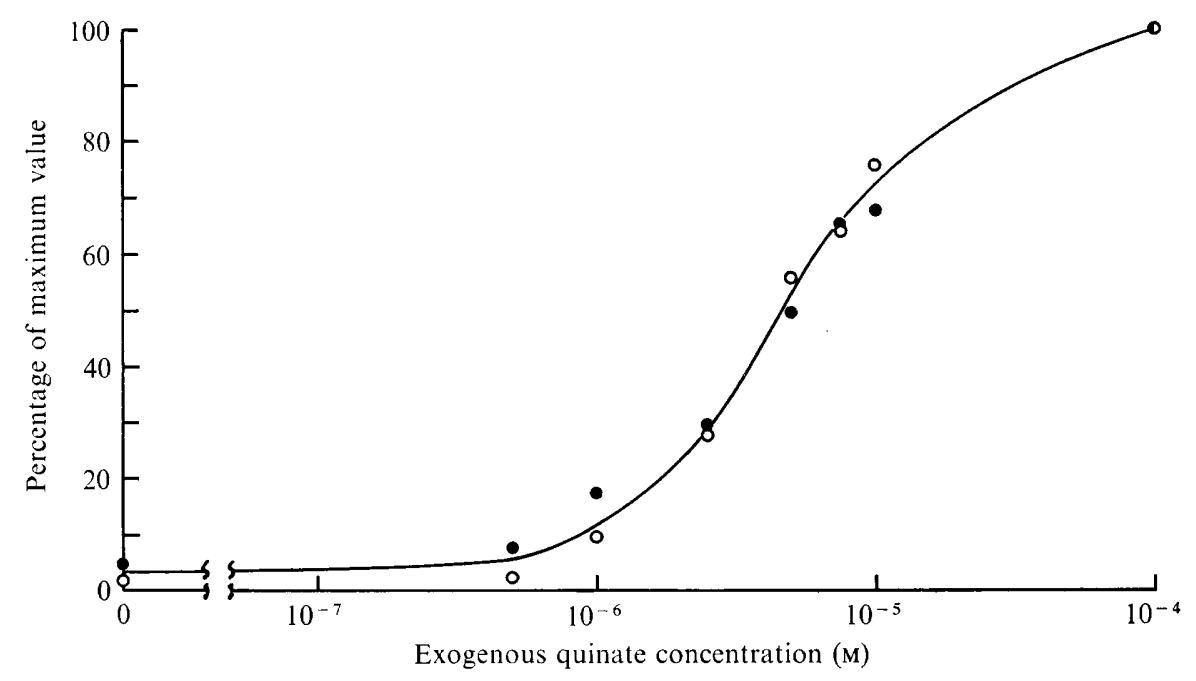

Fig. 4. Induction profile: cultures of a $q a-3$ strain (MI6-IA) were grown on sucrose minimal medium for $30 \mathrm{~h}$ and were shifted to an induction medium containing the indicated concentration of quinate and $1.5 \%$ glycerol. Cultures were harvested after $2 \mathrm{~h}$ and were extracted by Procedure II. 9 , catabolic dehydroquinase; $O$, DHS dehydrase.

\section{Table 4. Specificity of enzyme induction}

\begin{tabular}{|c|c|c|c|c|c|c|}
\hline \multirow{3}{*}{$\begin{array}{c}\text { Quinate } \\
\text { concentration } \\
\text { (M) }\end{array}$} & \multicolumn{6}{|c|}{ Specific activities in extracts* } \\
\hline & \multicolumn{3}{|c|}{$q a-3$ (MI6-IA) } & \multicolumn{3}{|c|}{$q a-4$ (MI8-IA) } \\
\hline & $\begin{array}{c}\text { Catabolic } \\
\text { DHQase }\end{array}$ & $\begin{array}{c}\text { DHS } \\
\text { reductase }\end{array}$ & $\begin{array}{c}\text { PCA } \\
\text { oxygenase }\end{array}$ & $\begin{array}{c}\text { Catabolic } \\
\text { DHQase }\end{array}$ & $\begin{array}{c}\text { DHS } \\
\text { reductase }\end{array}$ & $\begin{array}{c}\text { PCA } \\
\text { oxygenase }\end{array}$ \\
\hline 0 & $4 \cdot 6$ & $29 \cdot 2$ & 0.9 & 0 & N.T. & 0.3 \\
\hline $5.0 \times 10^{-7}$ & $50 \cdot 9$ & $30 \cdot 2$ & $2 \cdot 2$ & N.T. & N.T. & N.T. \\
\hline $10^{-6}$ & $102 \cdot 2$ & $29 \cdot 4$ & $4 \cdot 2$ & N.T. & N.T. & N.T. \\
\hline $2.5 \times 10^{-6}$ & $164 \cdot 4$ & $29 \cdot 3$ & $7 \cdot 4$ & N.T. & N.T. & N.T. \\
\hline $5.0 \times 10^{-6}$ & $243 \cdot 3$ & $55 \cdot 9$ & $I I \cdot I$ & $2 \cdot 3$ & $25 \cdot 0$ & N.T. \\
\hline $7.5 \times 10^{-6}$ & $283 \cdot 8$ & $37 \cdot 8$ & $16 \cdot 0$ & N.T. & N.T. & N.T. \\
\hline $10^{-5}$ & $326 \cdot 1$ & $32 \cdot 7$ & I8. I & $8 \cdot 0$ & $32 \cdot 5$ & N.T. \\
\hline $2.5 \times 10^{-5}$ & N.T. & N.T. & N.T. & $17 \cdot 7$ & $30 \cdot I$ & N.T. \\
\hline $5.0 \times 10^{-5}$ & N.T. & N.T. & N.T. & 29.0 & 30.5 & N.T. \\
\hline $10^{-4}$ & $368 \cdot 8$ & 30.9 & $19 \cdot 6$ & $48 \cdot 7$ & 33.8 & 0.3 \\
\hline $10^{-3}$ & 326.6 & $27 \cdot 7$ & - & $58 \cdot 3$ & 28.0 & 0.6 \\
\hline
\end{tabular}

* Cultures were grown on sucrose minimal medium for $30 \mathrm{~h}$ and transferred to induction medium containing $\mathrm{I} \cdot 5 \%$ glycerol and the indicated level of quinate. Cultures of $q a-3$ mycelia were harvested following a $5 \mathrm{~h}$ induction period. Cultures of $q a-4$ mycelia were harvested following a $2 \mathrm{~h}$ induction period. All extracts were prepared by Procedure II. N.T. = Not tested.

of inducers differed from the initial concentration of quinate in the medium. Induction was probably promoted by a constantly changing mixture of DHQ, DHS and quinate. The induction of quinate-shikimate dehydrogenase exactly paralleled that of catabolic dehydroquinase (Fig. 7).' The fact that one-half maximal induction was attained with a lower concentration of quinate in the medium in a qa-3 strain than in $q a-4$ strain would indicate that quinate is a more effective inducer than DHQ and DHS. These results also suggest that the lower enzyme levels routinely observed in the wild type reflect a lower effective inducer concentration resulting from the degradation of quinate, and are not caused by the phenomenon 
of 'self-catabolite repression' which has been reported in the Escherichia coli arabinose system (Katz \& Englesberg, I97I). Both the $q a-3$ and $q a-4$ mutants were unable to convert quinate to utilizable energy sources, yet, because of the lower effective inducer concentration in the qa-4 strain, the rate of enzyme synthesis was lower than in a qa-3 strain grown in a medium which initially contained the same concentration of quinate.

The levels of catabolic dehydroquinase and DHS reductase were compared in $q a-3$ and $q a-4$ strains which had been induced for $5 \mathrm{~h}$ and $2 \mathrm{~h}$, respectively, on several concentrations of quinate (Table 4). In both strains catabolic dehydroquinase activity increased and DHS reductase activity remained constant as a function of inducer concentration. Thus, quinate specifically induced the catabolic enzymes and did not affect the synthetic rates of constitutive enzymes.

\section{Co-ordinacy of enzyme synthesis}

Fig. 5 is a plot of the ratios of QDH to SDH activity obtained under 38 different sets of conditions. Since the two dehydrogenase reactions are catalysed by a single protein (Chaleff, 1974), this plot is useful in determining the contribution to scatter from errors in the experimental system. A plot of DHS dehydrase activity as a function of catabolic dehydroquinase activity in experiments utilizing a qa-3 mutant is presented in Fig. 6. One set of points was obtained from cultures which were harvested after a $2 \mathrm{~h}$ induction period and the other set from cultures harvested following $5 \mathrm{~h}$ induction. The ratio of the two activities was constant for each induction period, but the ratio was lower after $5 \mathrm{~h}$ induction than it was after $2 \mathrm{~h}$. These data may be explained by the differential lability of DHS dehydrase which has been demonstrated in this same $q a-3$ strain (Fig. 2). These results are consistent with co-ordinate regulation of catabolic dehydroquinase and DHS dehydrase.

Fig. 7 indicates that a strict proportionality was maintained between the levels of QDH and catabolic dehydroquinase over a wide range of specific activities. The data in Fig. 8 demonstrate that PCA oxygenase and catabolic dehydroquinase were not synthesized coordinately.

It was anticipated that the constitutive $\left(q a-I^{\mathrm{C}}\right)$ strains would be useful in studying the regulation of enzyme synthesis. A mutationally altered regulatory protein might display a different affinity from a $q a-I^{+}$protein for each of several possible regulatory sites. In constitutive strains grown on sucrose minimal medium for $30 \mathrm{~h}, \mathrm{QDH}, \mathrm{SDH}$ and catabolic dehydroquinase activities were maintained at a fairly constant level (Table 5). The in vivo lability of DHS dehydrase has been established in a qa-3 strain (Fig. 2). Therefore, although these results may suggest non-coordinacy, it is also possible that the levels of DHS dehydrase in the constitutive mutants reflect a steady-state situation in which the rate of synthesis is equal to the rate of degradation.

The ratios of QDH to catabolic dehydroquinase in five constitutive strains are plotted in Fig. 9. The points are more scattered than in Figs. 6 and 7, but a straight line which passes through the origin may still be drawn. To determine whether this increased scatter represents a breakdown of coordinate synthesis in the $q a-I^{\mathrm{C}}$ mutants, the in vivo stability of the two enzymes was measured in strain I24-RI5-I.2. The results (Fig. I0) show that QDH activity was lost more rapidly than was catabolic dehydroquinase activity, although both were unstable. Therefore it is probable that the greater variability of the ratio of these activities in constitutive strains results from the different rates at which they are denatured in vivo. These results indicate that the rate of enzyme synthesis cannot be measured quantitatively in the $q a-I^{\mathrm{C}}$ mutants. 


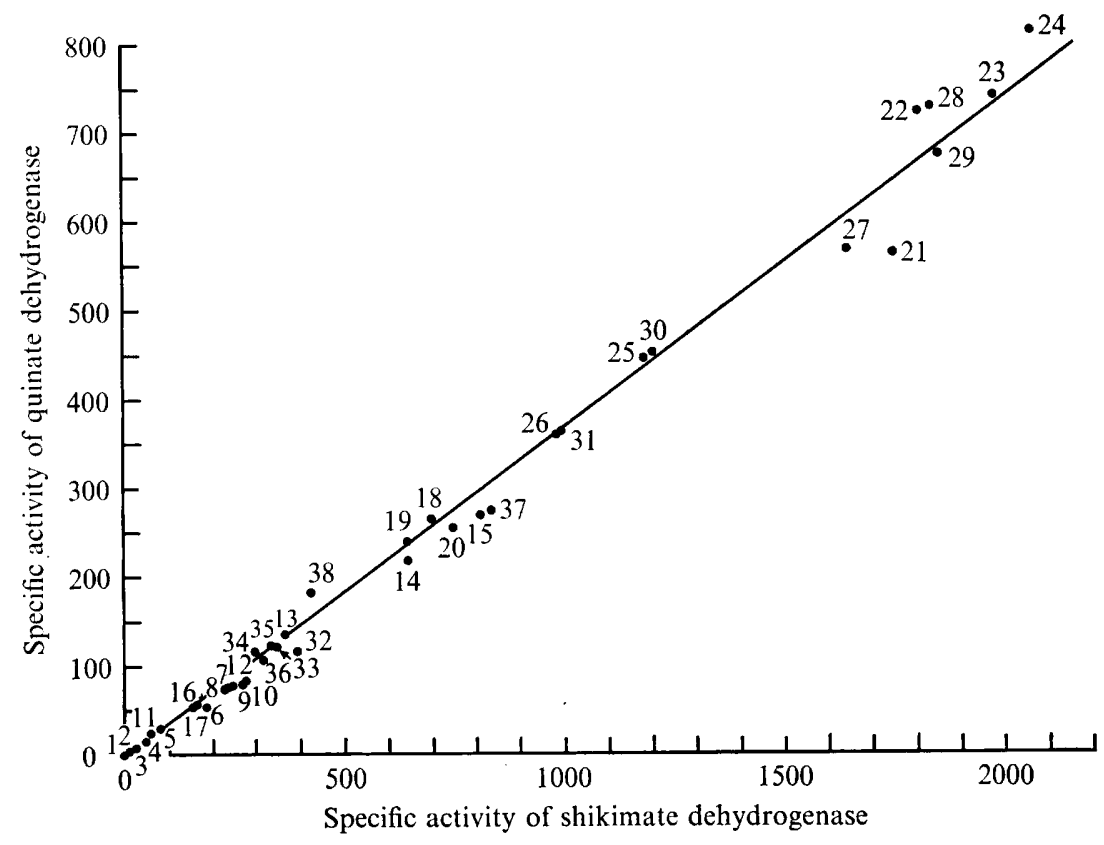

Fig. 5. QDH activity as a function of SDH activity in several strains grown under a wide variety of conditions. The origin of the points has been described previously (Chaleff, 1972).

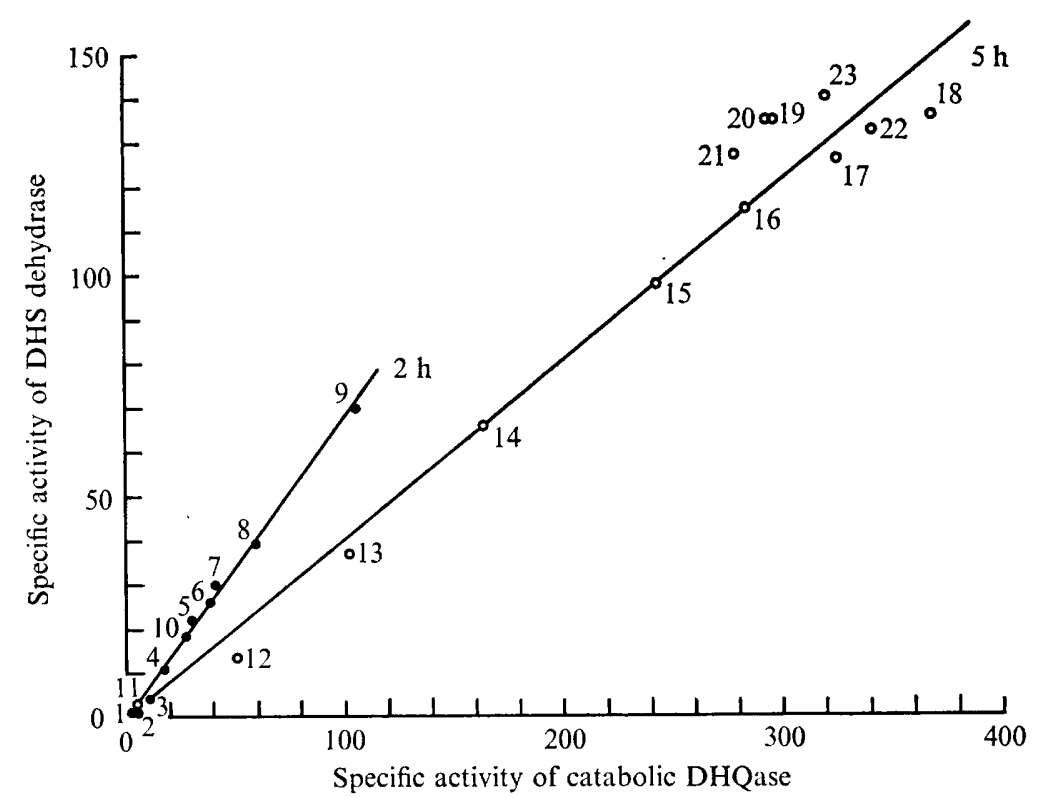

Fig. 6. DHS dehydrase activity as a function of catabolic dehydroquinase activity in qa-3 (MI6-IA) cultures grown under different conditions of induction. Cultures were harvested at or before $2 \mathrm{~h}(\boldsymbol{\theta})$ or at $5 \mathrm{~h}(\mathrm{O})$ of induction. The origin of the points has been described previously (Chaleff, 1972). 


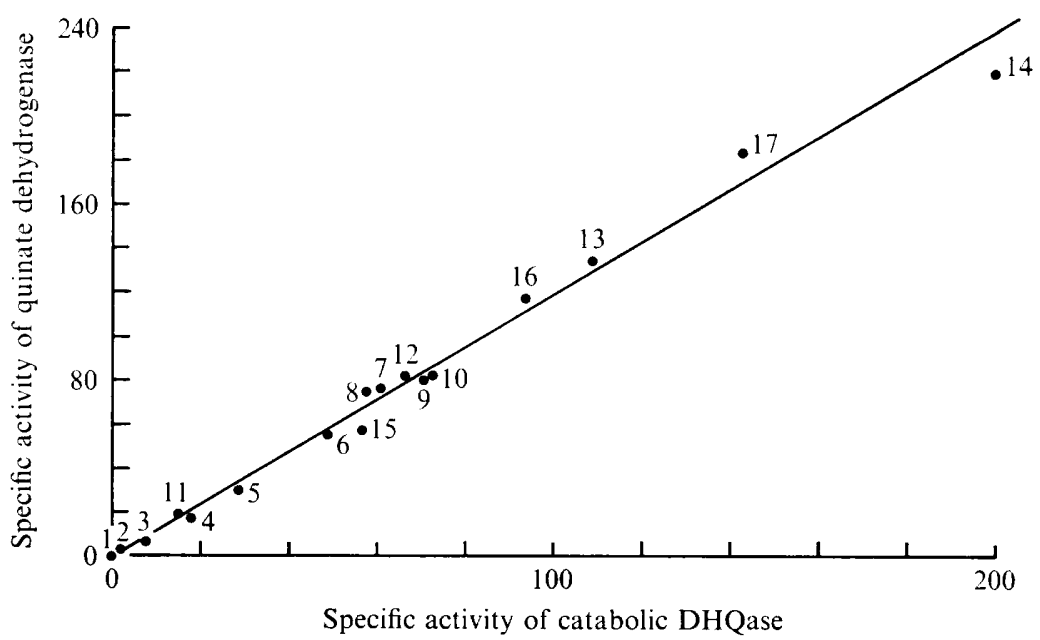

Fig. 7. Quinate dehydrogenase activity as a function of catabolic dehydroquinase activity in cultures of several strains grown under a wide variety of conditions. The origin of the points has been described previously (Chaleff, 1972).

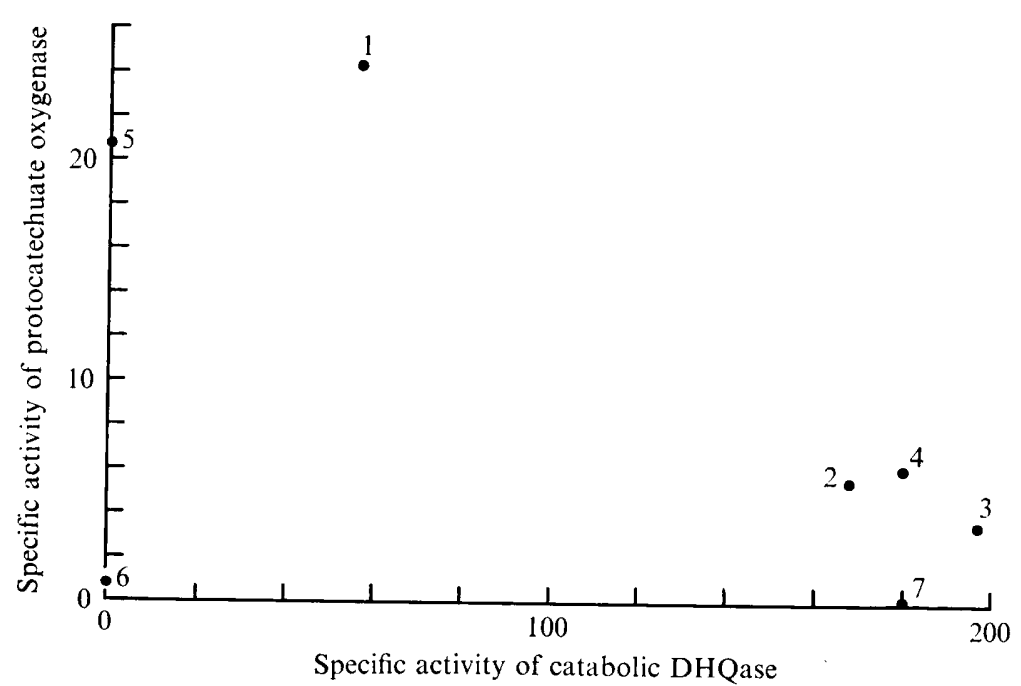

Fig. 8. Protocatechuate oxygenase activity as a function of catabolic dehydroquinase activity in cultures of several strains grown on sucrose medium for $30 \mathrm{~h}$ and shifted to $0.3 \%$ quinate medium for $5 \mathrm{~h}$. The origin of the points has been described previously (Chaleff, 1972).

\section{Competition between the catabolic and anabolic pathways}

The degree of competition between the catabolic and biosynthetic enzymes for the common intermediates DHQ and DHS may be determined quantitatively from the levels of PCA oxygenase in cultures in which the catabolic enzymes have been induced gratuitously. In this situation, PCA may be derived only by the action of the catabolic enzymes upon intermediates which are flowing through the biosynthetic pathway. This competition was achieved in the constitutive strains and in qa-3 mutants which were induced on quinate. Low, but 
Table 5. Enzyme levels in constitutive mutants

\begin{tabular}{|c|c|c|c|c|c|}
\hline \multirow[b]{2}{*}{ Strain } & \multicolumn{5}{|c|}{ Specific activities in extracts* } \\
\hline & QDH & $\mathrm{SDH}$ & $\begin{array}{l}\text { Catabolic } \\
\text { DHQase }\end{array}$ & $\begin{array}{c}\text { DHS } \\
\text { dehydrase }\end{array}$ & $\begin{array}{c}\text { PCA } \\
\text { oxygenase }\end{array}$ \\
\hline I40-R6-4. 5 & $200 \cdot 0$ & $628 \cdot 2$ & $235 \cdot 0$ & $18 \cdot 7$ & $4 \cdot 9$ \\
\hline I 24-R8-I . I & $276 \cdot 0$ & $784 \cdot 4$ & $289 \cdot 7$ & $18 \cdot 6$ & $3 \cdot 4$ \\
\hline I 24 -R I 5-I . 2 & $222 \cdot 7$ & $644 \cdot 5$ & 176.6 & $18 \cdot 0$ & 3.0 \\
\hline I05-RI 2-I. 5 & $247^{\circ} \circ$ & $802 \cdot I$ & $255 \cdot 7$ & $23 \cdot I$ & $6 \cdot 9$ \\
\hline I I 2-R29-I . I & 175.0 & $537 \cdot 4$ & $169 \cdot 3$ & I9.3 & $3 \cdot 0$ \\
\hline 74A (wild type) & 0.0 & $5 \cdot 1$ & 0.0 & 0.7 & 0.0 \\
\hline
\end{tabular}

* Cultures were grown on sucrose minimal medium for $30 \mathrm{~h}$ and were extracted by Procedure II.

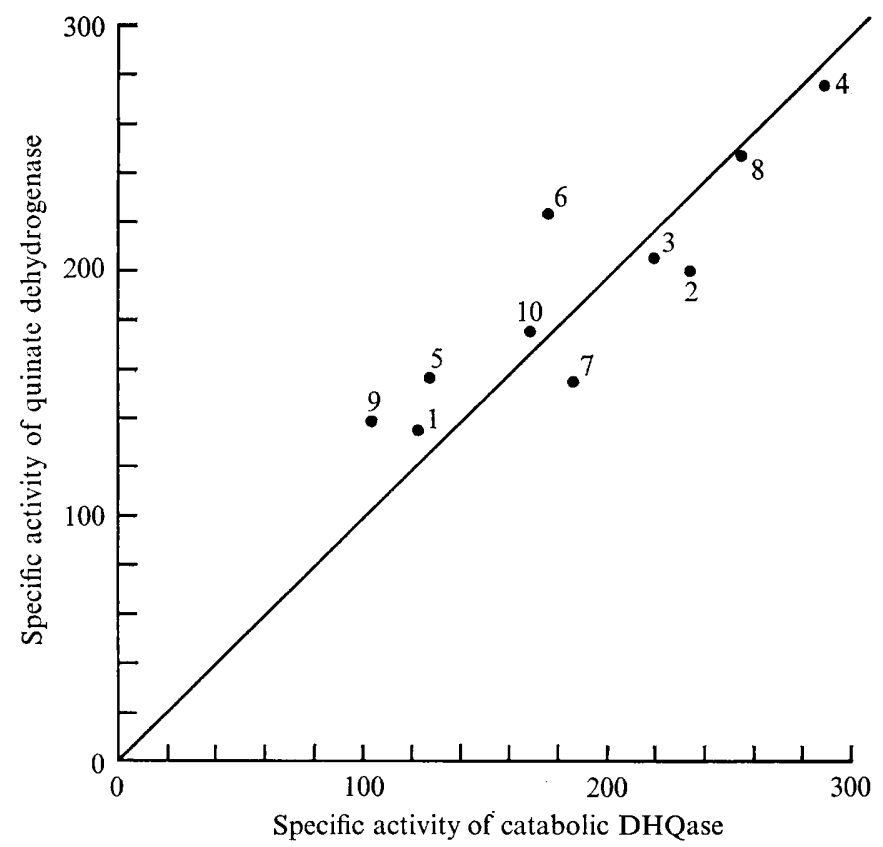

Fig. 9. Quinate dehydrogenase activity as a function of catabolic dehydroquinase activity in five constitutive $\left(q a-I^{\circ}\right)$ strains grown on sucrose minimal medium for $30 \mathrm{~h}$. The origin of the points has been described previously (Chaleff, 1972).

significant, levels of PCA oxygenase were found in both cases (Tables 4, 5). Since PCA oxygenase was absent from an induced $q a-4$ mutant (Table 4 ), this conversion of the biosynthetic intermediates to PCA is mediated by DHS dehydrase.

\section{DISCUSSION}

Several excellent studies have defined the concept of a differential rate of enzyme synthesis and the gratuitous conditions under which this cellular parameter may be determined in bacteria (Monod, 1956; Cohn, 1957; Herzenberg, 1959; Jacob \& Monod, 1961). However, gratuitous conditions for enzyme induction in Neurospora could only be approximated. Cultures were grown on sucrose and shifted to a medium containing glycerol and the inducer. Ideally, the same carbon source should be used throughout the experiment, but enzyme 


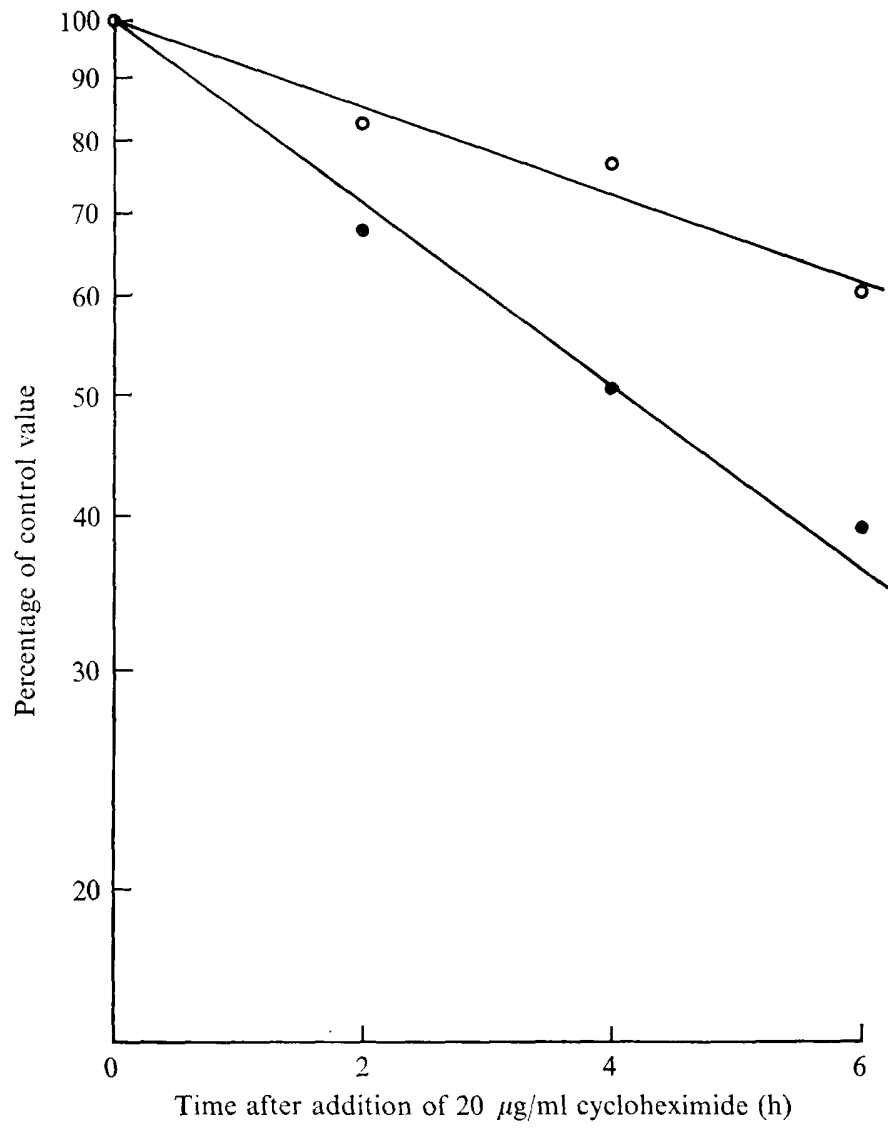

Fig. IO. Stability of quinate dehydrogenase and catabolic dehydroquinase in vivo. Cultures of constitutive strain I24-RI 5-I. 2 were grown on sucrose minimal medium. After 30 h cycloheximide was added to a final concentration of $20 \mu \mathrm{g} / \mathrm{ml}$. Cultures were harvested at the designated times and extracted by Procedure II. $0, \mathrm{QDH} ; \mathrm{O}$, catabolic dehydroquinase.

synthesis is repressed by sucrose and growth is extremely slow on glycerol, although this compound represses induction only slightly (Bates, 1969). Sufficient yields were not recovered if cultures were harvested while still in exponential phase on sucrose. The cultures were therefore allowed to grow for $30 \mathrm{~h}$ before being shifted to the fresh medium.

In the bacterial studies, total enzyme activity $\left(\Delta E+E_{0}\right)$ may be plotted against the mass of the culture $\left(\Delta M+M_{0}\right)$. In Neurospora cultures growing on glycerol induction medium, the increase in mass during the course of the experiment is so small that it is within experimental error. Therefore, in these studies enzyme activities are reported as a function of absolute $(\Delta t)$, rather than physiological $(\Delta M)$, time. However, because little or no growth occurs during the induction period, interference with the rate of enzyme formation from physiological factors is minimal. This approximation is also implicit in studies which measure bacterial enzyme synthesis over very short periods of time (Kepes, 1963).

Because Neurospora cells remain associated during growth, the kinetics of enzyme synthesis cannot be followed in a single culture. Therefore, instead of plotting the increase in enzyme activity $\left(\Delta E+E_{0}\right)$ versus the increase in mass $\left(\Delta M+M_{0}\right)$ to determine the differential synthetic rate, in these studies $\left(\Delta E+E_{0}\right) /\left(\Delta M+M_{0}\right)$ was plotted against $\Delta t$. However, 
since basal enzyme levels $\left(E_{0}\right)$ are barely detectable and $\Delta M$ is negligible, this function reduces to $\Delta E / M_{0}$. Because $M_{0}$ is a constant, plotting $\Delta E / M_{0}$ instead of $\Delta E$ does not affect the shape of the curve.

No gratuitous inducers of the $q a$ catabolic enzymes are yet available. A constant inducer concentration was maintained by employing mutants which are blocked in the utilization of quinate. Using these methods, a linear increase in enzyme activity as a function of time is obtained. It is assumed that steady-state conditions are most closely approximated during the period over which this linear increase in activity occurs. The rate of appearance of activity in this interval is referred to as the 'steady-state differential rate of enzyme synthesis'. Monod (1956) has shown this differential rate of enzyme synthesis to be dependent upon inducer concentration. The measurement of this steady-state differential rate in cultures of a qa-3 strain containing different concentrations of quinate has allowed the construction of a plot of the steady-state differential rate of enzyme synthesis as a function of inducer concentration (the induction profile). In these studies, half-maximal induction of the catabolic enzymes was obtained with $5 \times 1 \mathrm{IO}^{-6} \mathrm{M}$-quinate. This is the same as the concentration of allolactose, the apparent inducer of the lac operon in Escherichia coli, which is required to dissociate one-half of the repressor-operator complexes on a membrane filter (Jobe \& Bourgeois, 1972). However, a consideration of the results of in vivo experiments conducted by Burstein, Cohn, Kepes \& Monod (1965) may provide a more direct comparison between the Neurospora quinate and the $E$. coli lac systems. These authors reported half-maximal induction of the lac enzymes by $5 \times 10^{-8} \mathrm{M}-\mathrm{I}-O-\beta$-D-galactosyl-glycerol. Investigations of the arabinose operon of $E$. coli determined that half-maximal induction of these enzymes occurs at $\mathrm{IO}^{-4} \mathrm{M}$-arabinose in strain $\mathrm{KI} 2$ (Schleif, 1969) and at $6 \times 10^{-3} \mathrm{M}$ in strain $\mathrm{B} / \mathrm{r}$ (Doyle, Brown, Hogg \& Helling, 1972). Thus, provided quinate is not concentrated intracellularly, synthesis of the quinate-shikimate catabolic enzymes is controlled by a very sensitive regulatory mechanism.

One of our aims was to determine whether the quinate-shikimate catabolic enzymes are synthesized co-ordinately. Proof of co-ordinacy is based on negative evidence; that is, it can only be stated that conditions have not been found under which synthesis is non-coordinate. This investigation has examined the steady-state rates of synthesis in the presence of several concentrations of inducer and the kinetics of enzyme synthesis. The results are consistent with co-ordinate regulation of the catabolic enzymes. However, it must be emphasized that enzyme synthesis was examined over a very narrow range of conditions. Co-ordinacy is not a necessary concomitant of clustered genes. Douglas \& Hawthorne (1964) suggest that the three enzymes of the galactose pathway in yeast which are encoded in contiguous genes are not synthesized co-ordinately. Four enzymes which function in arginine biosynthesis in Escherichia coli are not repressed co-ordinately, although these enzymes are encoded in a four-gene cluster (Vogel, McClellan, Hirvonen \& Vogel, I97I). Several clustered genes of the $\beta$-ketoadipate pathway have been shown to be regulated independently in Pseudomonas aeruginosa (Kemp \& Hegeman, 1968; Rosenberg \& Hegeman, 1969) and in P. putida (Wheelis \& Stanier, 1970). Similarly, genes which specify separately inducible enzymes of benzoate and mandelate metabolism are co-transducible in $P$. aeruginosa (Rosenberg, I97I ; Rosenberg \& Hegeman, I97I). It is also apparent that co-ordinate synthesis is not a property peculiar to operons. In Neurospora two enzymes of the leucine biosynthetic pathway are synthesized co-ordinately, although the genes which specify these enzymes are unlinked (Gross, 1965). Therefore the demonstration that functionally related genes are clustered and are regulated co-ordinately does not constitute proof that these genes are organized as an operon.

The quantitative measurement of enzyme synthesis has been complicated by turnover of 
the catabolic enzymes. DHS dehydrase is more labile in vivo than are the first two enzymes of the pathway. This differential lability may be important in regulating the flow of metabolic intermediates. DHS represents a critical point of divergence for the catabolic and biosynthetic pathways. Studies with mutants have shown that the DHS which is synthesized by catabolic dehydroquinase may enter the biosynthetic pathway. The presence of PCA oxygenase in strains in which the catabolic enzymes are synthesized gratuitously indicates that DHS formed by an intact biosynthetic aggregate can be converted to PCA. This essentially irreversible conversion must limit the availability of DHS as a biosynthetic intermediate. This implies that the competition between DHS dehydrase and DHS reductase for their common substrate requires strict regulation. Thus, the lability of DHS dehydrase may be viewed as the means by which the cell responds to a changed environment and guarantees that DHS is directed to the formation of the aromatic amino acids.

Giles et al. (1967) originally proposed that the clustering of the arom genes in Neurospora may serve to facilitate the formation of the enzyme aggregate which functions as a channelling mechanism' to prevent degradation of essential biosynthetic intermediates by the competing catabolic pathway. However, metabolic channelling is not the only means by which the catabolism of essential biochemicals may be restricted. In many species of bacteria, enzymes which degrade tryptophan and histidine are induced by the products of the reactions which they catalyse. These observations suggest that regulatory systems may have evolved which prevent endogenous induction of catabolic enzymes and the subsequent dissimilation of biosynthetically formed metabolites (Palleroni \& Stanier, 1964; Ornston, I97I). Thus, if the primary function of the arom aggregate is to preclude competition for common intermediates by the biosynthetic and degradative pathways, the presence or absence of this aggregate should influence the evolution of the mechanism which governs the synthesis of the catabolic enzymes.

In Neurospora, at least one of the intermediates common to the two pathways (DHQ and DHS) functions as an inducer of the catabolic enzymes. Shikimate is not an effective inducer. If it is assumed that biosynthetically formed DHQ and DHS are retained completely by the aggregate, but that significant leakage of shikimate occurs, this specificity of induction is understandable.

I am indebted to Dr N. H. Giles for his support and constructive criticism and thank Drs G. Meyers, L. N. Ornston, C. W. H. Partridge, M. Berlyn, C. Doy and P. Carlson for their stimulating and critical discussion. This research was supported by Public Health Service Genetics Training Grant GM 397 and by Atomic Energy Commission Contract AT(30-I)-3098, both administered by Dr N. H. Giles.

\section{REFERENCES}

AmES, B. N. \& GARRY, B. (1959). Coordinate repression of the synthesis of four histidine biosynthetic enzymes by histidine. Proceedings of the National Academy of Sciences of the United States of America 45, 1453-1461.

AmEs, B. N. \& MARTIN, R. (I964). Biochemical aspects of genetics: the operon. Annual Review of Biochemistry 33, $235^{-258 .}$

Bates, W. K. (1969). Glycerol as carbon source for induction studies in Neurospora crassa. Neurospora Newsletter 14, II-12.

Burstein, C., Cohn, M., Kepes, A. \& Monod, J. (1965). Rôle du lactose et de ses produits métaboliques dans l'induction de l'opéron lactose chez Escherichia coli. Biochimica et biophysica acta 95, 634-639.

CASE, M. E. (1972). Genetical and biochemical characteristics of qa-I mutants in Neurospora crassa. Genetics 7I, Sio.

ChalEFF, R. S. (1972). Studies on the genetic control of the inducible quinate-shikimate catabolic pathway in Neurospora crassa. Ph.D. Dissertation, Yale University, U.S.A. 
CHALEFF, R. S. (1974). The inducible quinate-shikimate catabolic pathway in Neurospora crassa. Genetic organization. Journal of General Microbiology 8r, 337-355.

CoHn, M. (1957). Contributions of studies on the $\beta$-galactosidase of $E$. coli to our understanding of enzyme synthesis. Bacteriological Reviews 2I, I40-168.

Douglas, H. C. \& HAWTHORNE, D. C. (1964). Enzymatic expression and genetic linkage of genes controlling galactose utilization in Saccharomyces. Genetics 49, 837-844.

Doyle, M. E., Brown, C., Hogg, R. \& Helling, R. (r972). Induction of the ara operon of E. coli $\mathrm{B} / \mathrm{r}$. Journal of Bacteriology II0, 56-65.

Giles, N. H., Partridge, C. W. H., Ahmed, S. I. \& Case, M. E. (1967). The occurrence of two dehydroquinases in Neurospora crassa, one constitutive and one inducible. Proceedings of the National Academy of Sciences of the United States of America 58, 1930-1937.

Gross, S. R. (1965). The regulation of synthesis of leucine biosynthetic enzymes in Neurospora. Proceedings of the National Academy of Sciences of the United States of America 54, 1538-1546.

Hawley, E. S. \& Greenawalt, J. W. (1970). An assessment of in vivo mitochondrial protein synthesis in Neurospora crassa. Journal of Biological Chemistry 245, 3574-3583.

HerzenBerg, L. A. (1959). Studies on the induction of $\beta$-galactosidase in a cryptic strain of E. coli. Biochimica et biophysica acta 31, 525-538.

JACOB, F. \& MONOD, J. (1961). Genetic regulatory mechanisms in the synthesis of proteins. Journal of Molecular Biology 3, 318-356.

Jobe, A. \& Bourgeors, S. (1972). lac repressor-operator interaction. VI. The natural inducer of the lac operon. Journal of Molecular Biology 69, 397-408.

KATZ, L. \& ENGLESBERG, E. (197I). Hyperinducibility as a result of mutation in structural genes and selfcatabolite repression in the ara operon. Journal of Bacteriology 107, 34-52.

Kemp, M. B. \& Hegeman, G. D. (I968). Genetic control of the $\beta$-ketoadipate pathway in Pseudomonas aeruginosa. Journal of Bacteriology 96, 1488-I499.

KEPES, A. (1963). Kinetics of induced enzyme synthesis. Determination of the mean life of galactosidasespecific messenger RNA. Biochimica et biophysica acta 76, 293-309.

MoNOD, J. (1956). Remarks on the mechanism of enzyme induction. In Enzymes: Units of Biological Structure and Function, pp. 7-28. Edited by O. H. Gaebler. New York: Academic Press.

ORNSTON, L. N. (1971). Regulation of catabolic pathways in Pseudomonas. Bacteriological Reviews 35, 87-I I6.

PaLL, M. L. (1966). The use of cycloheximide as an inhibitor of protein synthesis in Neurospora. Neurospora Newsletter 9, 16-17.

Palleroni, N. J. \& Stanier, R. Y. (I964). Regulatory mechanism governing synthesis of the enzymes for tryptophan oxidation by Pseudomonas fuorescens. Journal of General Microbiology 35, 319-334.

PARTRIDGe, C. W. H., CASE, M. E. \& Giles, N. H. (1972). Direct induction in wild-type Neurospora crassa of mutants $(q a-I)$ constitutive for the catabolism of quinate and shikimate. Genetics 72 , $4 \mathrm{I}$ I-4 $1 \mathrm{I}$.

RINES, H. W. (1969). Genetical and biochemical studies on the inducible quinic acid catabolic pathway in Neurospora crassa. Ph.D. Dissertation, Yale University, U.S.A.

Rines, H. W., CASE, M. E. \& GiLes, N. H. (I969). Mutants in the arom gene cluster of Neurospora crassa specific for biosynthetic dehydroquinase. Genetics 6r, 789-800.

RoSENBERG, S. L. (1971). Regulation of the mandelate pathway in Pseudomonas aeruginosa. Journal of Bacteriology 108, 1257-I269.

Rosenberg, S. L. \& Hegeman, G. D. (1969). Clustering of functionally related genes in Pseudomonas aeruginosa. Journal of Bacteriology 99, 353-355.

Rosenberg, S. L. \& Hegeman, G. D. (1971). Genetics of the mandelate pathway in Pseudomonas aeruginosa. Journal of Bacteriology 108, 1270-1276.

SCHLEIF, R. (1969). Induction of the L-arabinose operon. Journal of Molecular Biology 46, 197-199.

TATUM, E. L., Gross, S. R., Ehrensvärd, G. \& Garnjobst, L. (I954). Synthesis of aromatic compounds by Neurospora. Proceedings of the National Academy of Sciences of the United States of America 40, 271-276.

VALONE, J. A., CASE, M. E. \& Giles, N. H. (I97I). Constitutive mutants in a regulatory gene exerting positive control of quinic acid catabolism in Neurospora crassa. Proceedings of the National Academy of Sciences of the United States of America 68, 1555-1559.

Vogel, R. H., McClellan, W. L., Hirvonen, A. P. \& Vogel, H. J. (1971). The arginine biosynthetic system and its regulation. In Metabolic Regulation, pp. 464-488. Edited by H. J. Vogel. New York: Academic Press.

Wheelis, M. L. \& Stanier, R. Y. (1970). The genetic control of dissimilatory pathways in Pseudomonas putida. Genetics 66, 245-266. 